\title{
PERANCANGAN STAND WELDING SEBAGAI ALAT BANTU TRAINING PENGELASAN DENGAN METODE HOUSE OF QUALITY (STUDI KASUS: ART WELDING SCHOOL BATAM)
}

\author{
M. Ansar Bora ${ }^{1}$, Bustanil Yacob ${ }^{2}$ \\ ${ }^{1}$ Dosen Program Studi Teknik Industri, ${ }^{2}$ Mahasiswa Program Studi Teknik Industri \\ STT IBNU SINA Batam \\ Email : ansar uim05@yahoo.com
}

\begin{abstract}
ABSTRAK
Perancangan produk baru sebagian besar adalah berkenaan dalam hal operasional antara lain men-spesifikasikan produk-produk yang akan dibuat dimana hal tersebut adalah sebuah persyaratan untuk melakukan produksi. ualitas sebagai konsistensi peningkatan atau perbaikan atau penurunan variansi karakteristik di suatu produk (barang dan jasa) yang dihasilkan agar memenuhi kebutuhan yang telah dispesifikasikan guna meningkatkan kepuasan pelanggan internal atau pelanggan eksternal. Hasil penelitian segi kenyamanan stand welding, Stand welding ini mempunyai sistem flexible sehingga bisa diatur elevasinya sesuai posisi yang diinginkan siswa training sehingga memberikan rasa nyaman dan dapat mengurangi kelelahan yang berdampak pada kesehatan tubuh, Stand welding ini menggunakan sistem jepit dan dilengkapi pengunci sehingga dapat mempermudah dalam pemasangan dan pelepasan material training sehingga sangat praktis dan aman digunakan. Dalam menentukan target pencapaian untuk setiap karakteristik teknik pada rumah kualitas, ditentukan target yang harus dicapai untuk masing-masing karakteristik teknik, tingkat kesulitan pembuatan produk, tingkat kepentingan dan perkiraan biaya tingkat masingmasing karakteristik teknik. Berikut total bobot dari target pencapaian produk stand welding: (a) Tingkat Kesulitan dengan total bobot $=74$, (b) Tingkat Kepentingan dengan total bobot $=318$, (c) Perkiraan Biaya dengan total bobot $=16$
\end{abstract}

Kata Kunci: Stand Welding, House of Quality

\section{PENDAHULUAN}

\subsection{Latar Belakang}

Batam sebagai kota industri banyak menggunakan pengelasan dalam proses manufaktur. Lingkup penggunaan pengelasan sangat luas dan universal meliputi pengeboran minyak lepas pantai, perkapalan, kontruksi alat berat, jembatan, rangka baja kendaraan, rel, konveyor dan lain sebagainya. Hal ini menunjukkan bahwa pengelasan digunakan bukan hanya untuk pembebanan-pembebanan statis tetapi juga ditujukan untuk pembebanan dinamis, sifat mekanik pengelasan seperti kekuatan, ketangguhan, ketahanan lelah dan lainnya diharapkan mampu menerima pembebanan yang ada, agar dalam penggunaannya tidak mengalami kegagalan.

Oleh karena itu proses pelatihan pengelasan harus memerlukan alat bantu penyangga material yang praktis dan sesuai dengan kebutuhan segala posisi pengelasan yang akan memudahkan dan memberikan kenyamanan siswa training dalam peraktek mengelas. 


\subsection{Rumusan Masalah}

Berdasarkan latar belakang diatas maka dapat dirumuskan permasalahan dalam penelitian ini yaitu bagaimana merancang stand welding sebagai alat Bantu Training Pengelasan Dengan Metode House Of Quality.

\subsection{Tujuan Penelitian}

Menghasilkan rancangan alat bantu training pengelasan yang dapat memberikan kenyamanan posisi siswa training dalam praktek pengelasan di berbagai macam posisi.

\subsection{Manfaat Penelitian}

Adapuns hasil penelitian ini diharapkan dapat bermanfaat untuk :

1. Memudahkan posisi pengelasan siswa training sesuai dengan posisi yang diinginkan berdasarkan kenyamanan.

2. Memudahkan dalam peletakan material terhadap posisi pengelasan.

3. Mengetahui cara membuat stand welding.

\section{METODOLOGI PENELITIAN}

\subsection{Tempat Penelitian}

Penelitian ini dilaksanakan pada bulan Februari 2015 sampai dengan bulan Juli 2015. Lokasi penelitian ini dilaksanakan di Art Welding School Batam. Komplek Ruko Bandara Mas Blok A No.8, Batam CentreBatam.

\subsection{Jenis Penelitian}

Dalam pengumpulan data untuk penelitian ini, maka jenis data yang dikumpulkan yaitu :

Data primer merupakan sumber data yang diperoleh langsung dari sumber asli (tidak melalui media perantara). Adapun data primer yang dilakukan dalam penelitian ini adalah sebagai berikut: (a) Ukuran produk, (b) material yang dibutuhkan, dan (c) peralatan yang dibutuhkan.

Data Sekunder, data yang diperoleh dari berbagai sumber bacaan maupun informasiinformasi dari media massa dan elektronik serta tulisan-tulisan yang berhubungan dengan proses desain pengembangan produk seperti dengan menggunakan metode QFD.

\subsection{Metode Pengumpulan Data}

Untuk mengumpulkan data yang diperlukan dalam penelitian ini, penulis menggunakan teknik sebagai berikut :

- Pengamatan langsung (observation) ke lokasi penelitian untuk mendapatkan data yang diperlukan agar dapat digali sesuai dengan kenyataan sekaligus mengukur kebenaran dari hasil wawancara langsung dengan siswa mengenai proses praktek pangelasan.

- Menyebarkan kuisioner kepada seluruh siswa training mengenai keinginan siswa tentang alat bantu pada proses Training pengelasan di Art Welding School Batam.

\subsection{Metode Pengolahan Data}

\section{Uji Validitas}

$$
\mathrm{Rxy}=\frac{N \sum x y-\left(\sum x\right)\left(\sum y\right)}{\left|\sqrt{\left(N \sum X^{2}-\left(\sum x\right)^{2}\right)\left(N \sum Y^{2}-\left(\sum Y\right)^{2}\right)}\right|}
$$

\section{Uji Realibility}

$\mathrm{r}=\left[\frac{k}{k-1}\right]\left[1-\frac{\Sigma \alpha^{2} \mathrm{~b}}{\alpha^{2} \mathrm{t}}\right]$

Adapun simbol-simbol yang digunakan dalam pengisian House Of Quality adalah sebagai berikut:

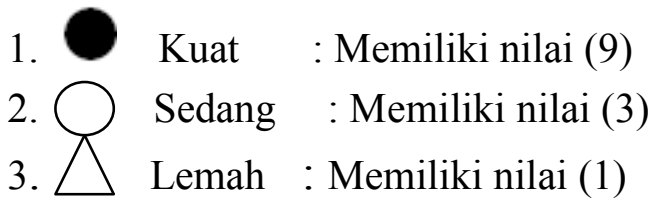

\section{ANALISA DAN PEMBAHASAN}

Berdasarkan hasil penelitian tingkat kepentingan, tingkat kepuasan dan tingkat harapan, maka rumah kualitas quality function development seperti gambar dibawah ini:

\subsection{Analisa QFD}



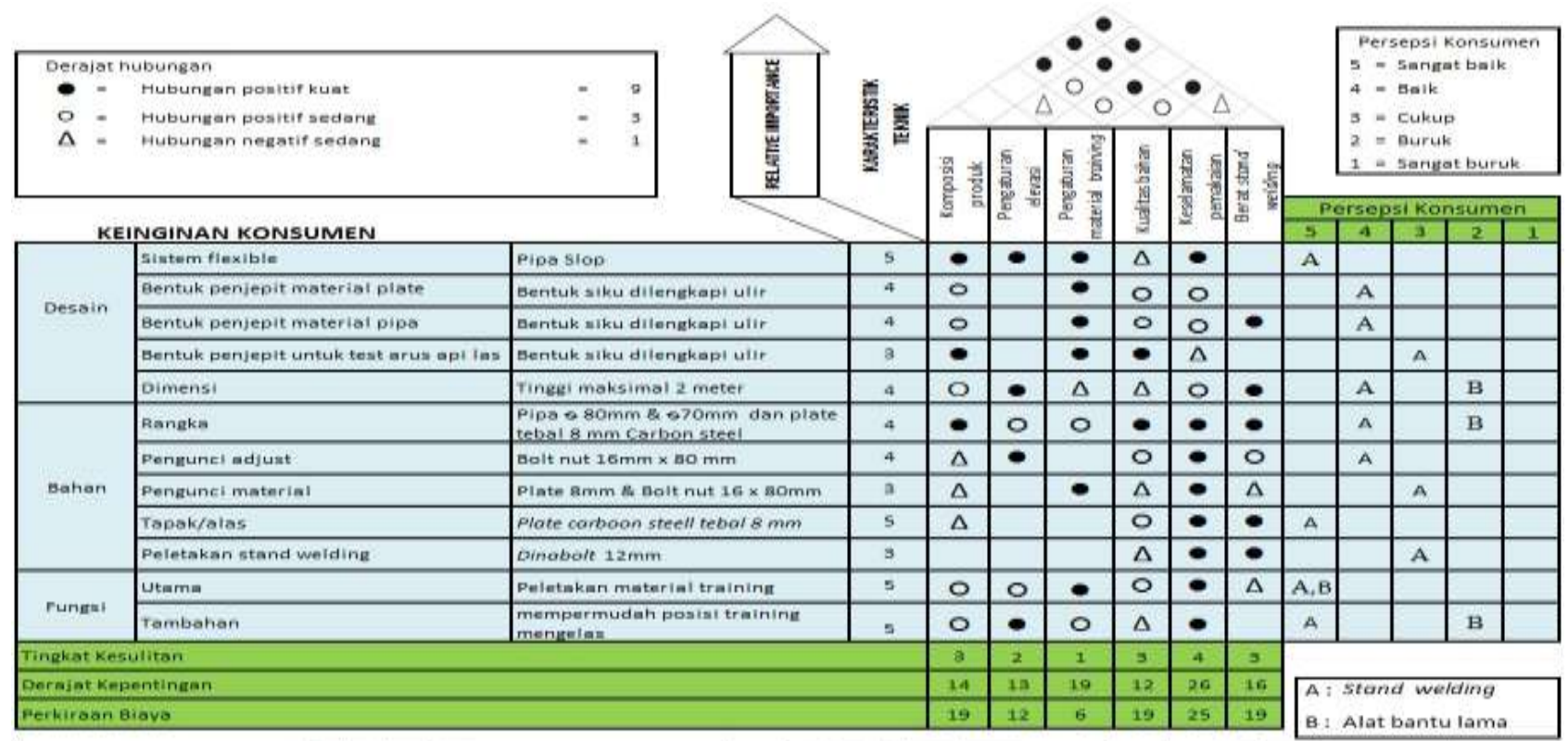

\begin{tabular}{|c|c|c|}
\hline \multirow{5}{*}{ Desain } & Sinterm flexible & Pipa slop \\
\hline & Bentuk penjepit material plate & Bentuk siku dilensikapi u \\
\hline & Bentuk penjepit material pipa & Dentuk niku dilengkapi L \\
\hline & Bentuk penjepit untuk test arus api las & Bentuk siku dilengkaply \\
\hline & Dimensi & Tinesi maksimal 2 meter \\
\hline & Rangka & $\begin{array}{l}\text { Pipa a } 80 \mathrm{~mm} \text { Be }=70 \mathrm{~mm} \\
\text { tebal } 8 \mathrm{~mm} \text { carbon stecl }\end{array}$ \\
\hline & Pengunel adjuat: & Bolt nut $16 \mathrm{~mm} \times 80 \mathrm{~mm}$ \\
\hline Bahan & Pengunci material & Plate $8 \mathrm{~mm}$ \& Dolt nut 16 \\
\hline & Tapak/alas & Plate carboon steell tebal \\
\hline & Peletakan stand weiding & Dinabole $12 \mathrm{~mm}$ \\
\hline \multirow{2}{*}{ rungat } & Utamm & Peletakan material train \\
\hline & Tambahan & $\begin{array}{l}\text { mempermudah posisi tr } \\
\text { menuelas }\end{array}$ \\
\hline \multicolumn{3}{|c|}{ Tingkat Kesulitan } \\
\hline \multicolumn{3}{|c|}{ Derainat Kepentingan } \\
\hline \multicolumn{3}{|c|}{ Perkiraan Biayo } \\
\hline \multicolumn{3}{|c|}{ Tingkat kesulitan } \\
\hline $\begin{array}{l}1= \\
3=\end{array}$ & $\begin{array}{l}\text { Mudah } \\
\text { cukup mudah }\end{array}$ & 2096 \\
\hline $5=$ & $\begin{array}{l}\text { Cukup mudah } \\
\text { sulit }\end{array}$ & 41. \\
\hline $7=$ & sangat sulit & $80 \%$ \\
\hline $9=$ & Mutiak sulit & 10096 \\
\hline
\end{tabular}
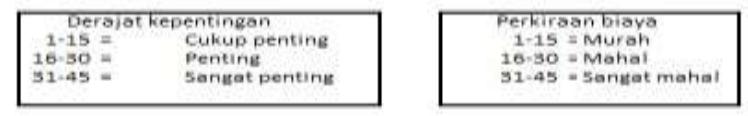

Gambar 1. Rumah kualitas perancangan stand welding

\subsection{Desain Alat Bantu Lama}

Berikut beberapa gambar alat bantu pengelasan yang lama:

a. Pada gambar dibawah ini menunjukkan bahwa posisi peserta training dalam mengelas terlihat tidak nyaman karena alat bantu yang lama hanya berbentuk seperti meja dan tidak bisa di adjust.

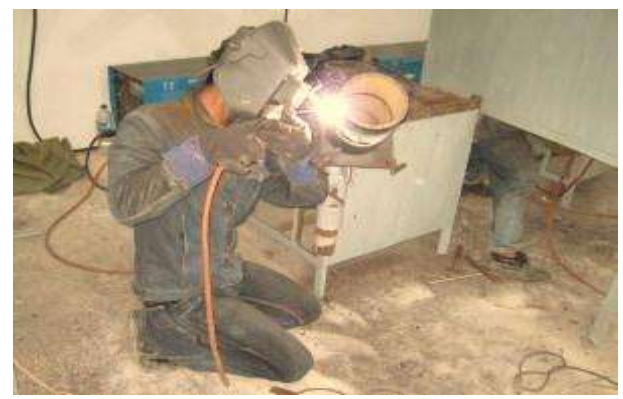

Gambar 2. Alat bantu lama b. Pada gambar dibawah ini menunjukkan bahwa peletakan material training tidak praktis karena menggunakan tig weld

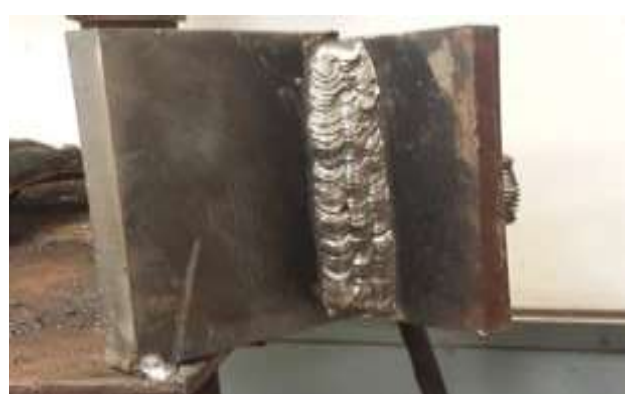

Gambar 3. Peletakan material pada alat bantu lama

\subsection{Desain Stand Welding}

Berikut beberapa gambar desain stand welding beserta keterangan dan fungsifungsinya. 


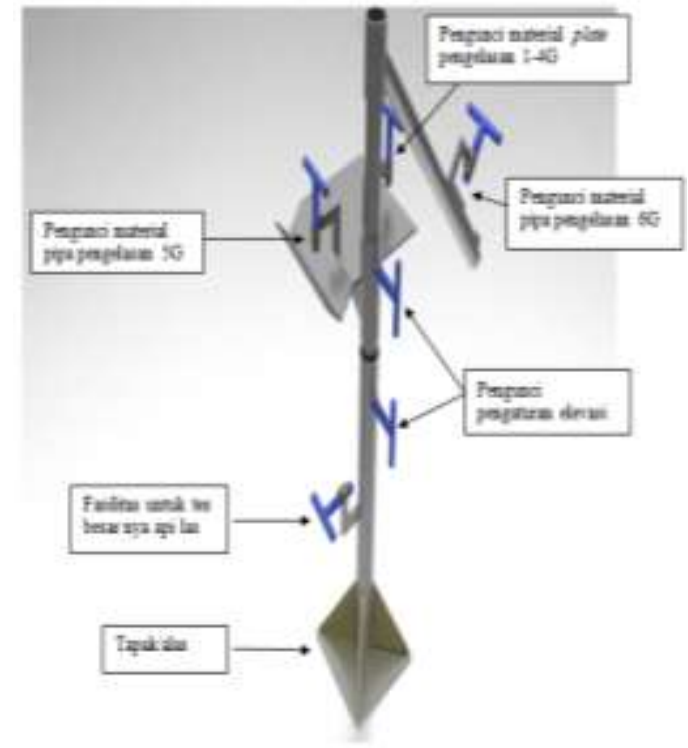

Gambar 4. Desain stand welding

\subsubsection{Pemasangan Material Training Pada Stand Welding}

Berikut beberapa gambar peletakan material Training pengelasan pada stand welding.

a. Posisi Material Normal

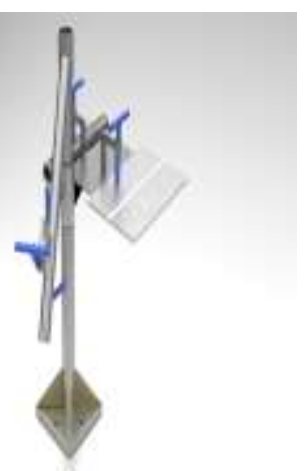

Gambar 6. Posisi material normal menggunakan stand welding

b. Posisi Material Horizontal

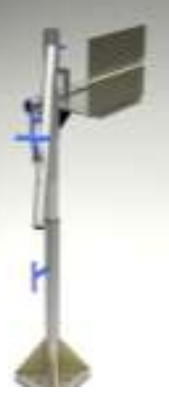

Gambar 7 Posisi material horizontal menggunakan stand welding c. Posisi Material Vertical

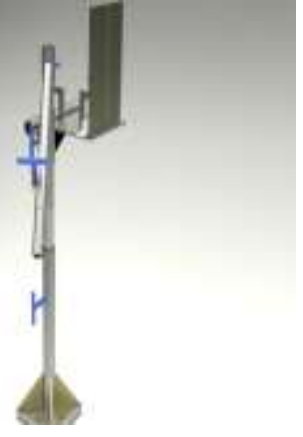

Gambar 4.8 Posisi material vertical menggunakan Stand welding

\section{d. Posisi Material Overhead}

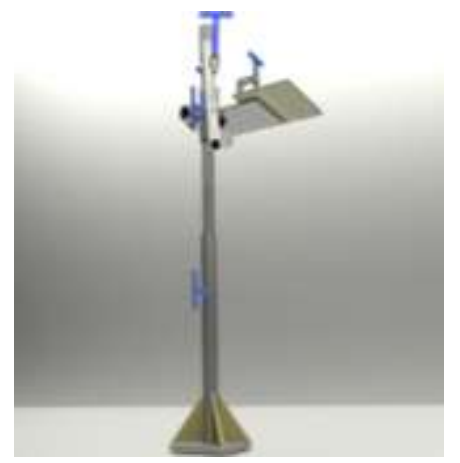

Gambar 8. Posisi material overhead menggunakan stand welding

e. Posisi Material Pipa 5G Dan 6G

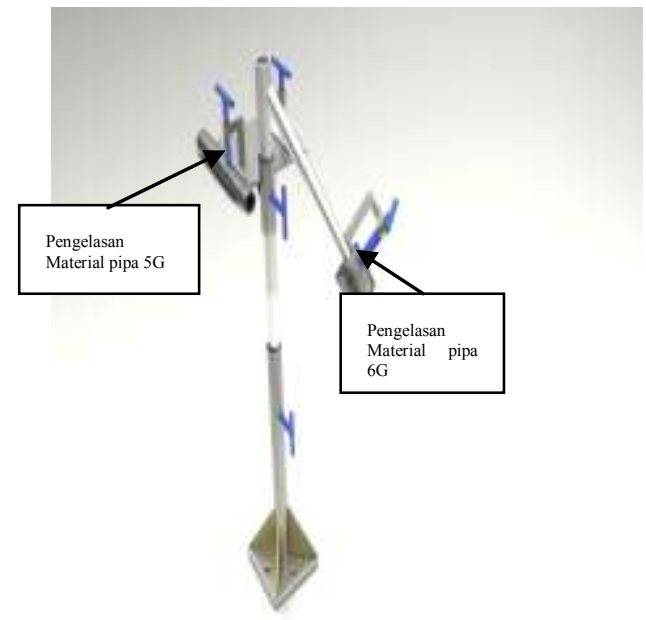

Gambar 9. Posisi material 5G dan 6G menggunakan stand welding

\section{Analisa Pembahasan}

Atribut stand welding dari kuisioner

a. Sistem flexible (Menggunakan pipa ) 
b. Penjepit material plate (plate siku dilengkapi ulir)

c. Penjepit material pipa (plate siku dilengkapi ulir)

d. Penjepit tes arus api las (plate siku dilengkapi ulir)

e. Dimensi (Tinggi maksimal 2 meter)

f. Rangka (Pipa $80 \mathrm{~mm} \&$ \& $70 \mathrm{~mm}$ dan plate tebal $8 \mathrm{~mm}$ Carbon steel)

g. Pengunci Adjust (Bolt nut $16 \mathrm{~mm} \times 80$ $\mathrm{mm} \&$ plate $8 \mathrm{~mm})$

h. Pengunci Material (Bolt nut $16 \mathrm{~mm} \times 80$ $\mathrm{mm} \&$ plate $8 \mathrm{~mm})$

i. $\quad$ Tapak/Alas (Plate carboon steell tebal 8 $\mathrm{mm})$

j. $\quad$ Peletakan stand welding (Dinabolt)

k. Fungsi utama (Peletakan material Training)

1. Fungsi Tambahan (Mempermudah posisi Training las)

\section{Hasil Perbandingan Stand Welding Dengan Alat Bantu Lama}

a. Sistem flexible : Stand welding menggunakan sistem flexible sedangkan alat bantu yang lama tidak

b. Penjepit material plate: Stand welding menggunakan sistem jepit sedangkan alat bantu yang lama tidak

c. Penjepit material pipa: Stand welding menggunakan sistem jepit sedangkan alat bantu yang lama tidak

d. Penjepit tes arus api las: Stand welding dilengkapi penjepit tes arus api las sedangkan alat bantu yang lama tidak

e. Dimensi: Tinggi Stand welding maksimal 2 meter sedangkan alat bantu yang lama 1 meter

$f$. Rangka: Stand welding dan alat bantu yang lama sama-sama terbuat dari carbon steel namun dengan desain yang berbeda

g. Pengunci adjust: Stand welding menggunakan pengunci adjust sedangkan alat bantu yang lama tidak

h. Pengunci Material: Stand welding menggunakan pengunci material training sedangkan alat bantu yang lama tidak i. Tapak/Alas: Stand welding menggunakan tapak/alas sebagai pondasi sedangkan alat bantu yang lama tidak

j. Peletakan: Stand welding menggunakan dinabolt sebagai pengaman sedangkan alat bantu yang lama tidak

k. Fungsi utama: Stand welding dan alat bantu yang lama sama-sama berfungsi sebagai peletakan material

l. Fungsi Tambahan: Stand welding lebih unggul dari alat bantu yang lama karena bisa di adjust sehingga lebih mempermudah posisi pengelasan sedangkan alat bantu yang lama tidak bisa di adjust.

\section{Tingkat Kesulitan}

1. Komposisi Produk : Mudah

2. Lama setting elevasi : Mudah

3. Lama setting material : Mudah

4. Kualitas bahan : Mudah

5. Keselamatan pemakaian : Cukup mudah

6. Berat stand welding : Mudah

\section{Tingkat Kepentingan :}

1. Komposisi Produk : Cukup penting

2. Lama setting elevasi : Cukup penting

3. Lama setting material : Penting

4. Kualitas bahan : Cukup penting

5. Keselamatan pemakaian ': Penting

6. Berat stand welding : Penting

Perkiraan Biaya :

1. Komposisi Produk : Mahal

2. Lama setting elevasi : Murah

3. Lama setting material : Murah

4. Kualitas bahan : Mahal

5. Keselamatan pemakaian ' : Mahal

6. Berat stand welding : Mahal

\section{PENUTUP}

\subsection{Kesimpulan}

Berdasarkan hasil penelitian yang telah dilakukan, maka penulis dapat menyimpulkan sebagai berikut :

1. Segi kenyamanan stand welding

a. Stand welding ini mempunyai sistem flexible sehingga bisa diatur elevasinya sesuai posisi yang diinginkan siswa 
training sehingga memberikan rasa nyaman dan dapat mengurangi kelelahan yang berdampak pada kesehatan tubuh

b. Stand welding ini menggunakan sistem jepit dan dilengkapi pengunci sehingga dapat mempermudah dalam pemasangan dan pelepasan material training sehingga sangat praktis dan aman digunakan

2. Dalam menentukan target pencapaian untuk setiap karakteristik teknik pada rumah kualitas, ditentukan target yang harus dicapai untuk masing-masing karakteristik teknik, tingkat kesulitan pembuatan produk, tingkat kepentingan dan perkiraan biaya tingkat masingmasing karakteristik teknik. Berikut total bobot dari target pencapaian produk stand welding: (a) Tingkat Kesulitan dengan total bobot $=74$, (b) Tingkat Kepentingan dengan total bobot $=318$, (c) Perkiraan Biaya dengan total bobot $=$ 16

\subsection{Saran}

1. Untuk penelitian selanjutnya stand welding lebih dikembangkan untuk memfasilitasi material pengelasan yang lebih besar.

2. Stand welding hendaknya dikembangkan agar bisa portatble sehingga bisa dibawa dan dipindah-pindah dengan mudah namun tetap memperhatikan keselamatan pemakaian.

3. Terus mangembangkan ide-ide yang positif dalam perancangan dan pengembangan produk.

\section{DAFTAR PUSTAKA}

Akao, Yoji. 1990. Introduction to Quality Deployment (Application Manual of Quality Function Deployment . Japanese: JUSE Press.

Cohen, Lou. 1995. Quality Function Deploymen "How to make QFD work for you" Addison Wesley Publishing Company : New York.
Djati, Imam Widodo . 2003. Perencanaan dan Pengembangan Produk. Ull Press : Jogjakarta.

Kotler, P. \& Amstrong, G. (2001). DasarDasar Pemasaran Edisi Kesembilan.

Jilid Satu. Jakarta : PT Indeks.

Permana, Rian. 2013. Desain Produk Holder Conector VGA dengan Quality Function Deployment. Bandung: Fakultas Teknik Industri Universitas Widyatama.

Rosnani Ginting. Perancangan Produk. Edisi pertama Yogyakarta, Graham Ilmu tahun 2010.

Sugiatno. 2013. Perancangan Ransel Infus Ergonomi Pada Ruang Rawat Inap Menggunakan Data Antropometri. Batam: Fakultas Teknik Industri STT Ibnu Sina.

Ulrich, Karl T., dan Eppinger Steven D., 2001. Perancangan Dan Pengembangan Produk. Salemba Teknika, Jakarta.

Windharto, S., 2007. Menuju Juru Las Tingkat Dunia. PT Pradnya Paramita, Jakarta 